\title{
The willingness of final year medical and dental students to perform bystander cardiopulmonary resuscitation in an Asian community
}

\author{
Keng Sheng Chew $•$ Mohd Noh Abu Yazid
}

Received: 18 August 2008 / Accepted: 17 September 2008 / Published online: 11 November 2008

(C) Springer-Verlag London Ltd 2008

\begin{abstract}
Background Despite the importance of early effective chest compressions to improve the chance of survival of an outof-hospital cardiac arrest victim, it is still largely unknown how willing our Malaysian population is to perform bystander cardiopulmonary resuscitation (CPR).

Aims We conducted a voluntary, anonymous self-administered questionnaire survey of a group of 164 final year medical students and 60 final year dental students to unravel their attitudes towards performing bystander CPR.

Methods Using a 4-point Likert scale of "definitely yes," "probably yes," "probably no," and "definitely no," the students were asked to rate their willingness to perform bystander CPR under three categories: chest compressions with mouth-to-mouth ventilation ( $\mathrm{CC}+\mathrm{MMV})$, chest compressions with mask-to-mouth ventilation $(\mathrm{CC}+$ $\mathrm{PMV}$ ), and chest compressions only (CC). Under each category, the students were given ten hypothetical victim scenarios. Categorical data analysis was done using the McNemar test, chi-square test, and Fisher exact test where appropriate. For selected analysis, "definitely yes" and "probably yes" were recoded as a "positive response."

Results Generally, we found that only $51.4 \%$ of the medical and $45.5 \%$ of the dental students are willing to perform bystander CPR. When analyzed under different hypothetical scenarios, we found that, except for the scenario where the victim is their own family member, all other scenarios showed a dismally low rate of positive responses in the category of $\mathrm{CC}+$
\end{abstract}

Disclaimer: The views expressed in this paper are those of the author (s) and not those of the editors, editorial board or publisher.

K. S. Chew $(\bowtie) \cdot$ M. N. A. Yazid

Emergency Medicine Department, School of Medical Sciences,

Universiti Sains Malaysia,

16150 Kubang Kerian, Kelantan, Malaysia

e-mail: cksheng74@yahoo.com
MMV, but their willingness was significantly improved under the CC + PMV and CC categories.

Conclusion This study shows that there are unique sociocultural factors that contribute to the reluctance of our students to perform CC + MMV.

Keywords Cardiopulmonary resuscitation .

Mouth-to-mouth resuscitation - Basic cardiac life support .

Asian community

\section{Introduction}

The ultimate aim of any basic life support (BLS) training course is not just to equip the health care providers [1-3] and lay rescuers [3-5] with the knowledge and skills to perform cardiopulmonary resuscitation (CPR), but also to cultivate a strong conviction among them to be willing to help should such an actual dire need arise [5, 6]. Time is of utmost importance in improving the chance of survival of a cardiac arrest victim $[7,8]$ as every minute delay without the initiation of BLS will decrease the chance of survival by $7-10 \%$ [9].

This is especially so if the time taken from the activation of the emergency medical services to the time when they arrive at the scene is longer than the critical first $5 \mathrm{~min}$ [10]. In Malaysia, this time interval is often 15-20 min at best [11-13].

Furthermore, as over $75 \%$ of all out-of-hospital cardiac arrests occur at home [14], there is a need to disseminate the knowledge and skills of BLS to a wider sphere of the Malaysian population, encompassing not just the uniformed members of society like the police and the fire squads, but also the ordinary citizens at home as well.

Although BLS courses have been organized by various professional bodies in Malaysia [13, 15], it is still largely unknown how prepared our Malaysian population is to 
translate what has been learned from the BLS training courses into the pragmatic willingness to perform CPR should such a potential life-saving measure be called for.

As far as we know, the only published Malaysian survey on this issue was one done in 2005, where it was found that only $52.7 \%$ of the health care staffs interviewed (comprising various categories including health directors, doctors, ward nurses, and community assistant nurses) said that they were confident and able to perform first aid and CPR [16].

We, therefore, conducted an opportunistic, voluntary, anonymous self-administered questionnaire survey to unravel the attitudes of our final year medical and dental students towards performing bystander CPR in a setting beyond the scope of their future professional call of duty. This survey was conducted in conjunction with the end of rotation emergency medicine examination.

\section{Methods}

Briefly, Malaysia $\left(2.30^{\circ} \mathrm{N}, 112.30^{\circ} \mathrm{E}\right)$ is a multi-ethnic, multi-religion country consisting of 13 states and 3 federal territories in Southeast Asia $[17,18]$. The majority of the Malaysian population of about 25 million people consists of the Malays (50.4\%); the other major ethnic groups include the Chinese $(23.7 \%)$, the indigenous groups $(11 \%)$, and the Indians (7.1\%) [17]. For the year 2006, the Malaysian crude death rate per 1,000 people was 4.5 [19]. The top three principal causes of death in our Ministry of Health hospitals were septicemia $(16.9 \%)$, heart diseases and diseases of pulmonary circulation $(15.7 \%)$, and malignant neoplasm $(10.6 \%)$ [19]. The doctor:population ratio in that year was $1: 1,214$ [19]. With such a doctor:population ratio coupled with a high death rate due to cardiopulmonary diseases, it points out all the more that the public should play an active role to improve the chance of survival of those who suffer a cardiac arrest in the out-of-hospital setting.

The undergraduate medical degree in the Universiti Sains Malaysia is an integrated, three-phase program based on the SPICES model $(\mathrm{S}=$ student-oriented, $\mathrm{P}=$ problembased, I = integrated, $\mathrm{C}=$ community-based, $\mathrm{E}=$ elective, and $\mathrm{S}=$ self-directed/systematic learning) [20, 21]. Under this system, the students go through the various biomedical disciplines in a spiral approach, where core subjects dealt with in the earlier phase are pursued again in a more indepth manner during the subsequent phases to ensure adequate breadth and depth of the various medical knowledge [20]. In the area of resuscitation, for example, in the first year of their medical education, the students are taught the basic principles and skills of first aid, including BLS, and in the final year, the knowledge and skills of BLS will be revisited together with the principles and practices of advanced cardiac life support (ACLS). In short, all medical students in the university will go through the principles and practices of BLS at least twice in their undergraduate years. The undergraduate dental degree is modeled on this system using a similar concept as for the medical degree.

The emergency medicine posting is a compulsory 2 -week rotation in the undergraduate medical and dental curriculum. It is during this rotation that batches of 20-25 medical and dental students are exposed to the various principles and practices of emergency medicine including BLS and ACLS in accordance with the 2005 American Heart Association (AHA) guidelines for CPR and emergency cardiovascular care [22]. At the end of the rotation, the students sit a written test and a structured clinical examination. For the academic year 2007-2008, there were a total of 164 final year medical students and 60 final year dental students.

Each student was given a set of questionnaire survey forms that consisted of three sections. Section A of the survey consisted of demographic entries, whereas in section $\mathrm{B}$, the students were asked a general question on what they would do should they witness any cardiac arrest in an out-of-hospital setting. Section $\mathrm{C}$ was subdivided into three categories, i.e., performing chest compressions with mouth-to-mouth ventilation (CC $+\mathrm{MMV})$, performing chest compressions with maskto-mouth ventilation (CC + PMV), and performing chest compressions only (CC). For each category, the students were asked to rate their willingness to perform bystander CPR under ten hypothetical scenarios using a 4-point Likert scale of "definitely yes," "probably yes," "probably no," and "definitely no." The ten hypothetical scenarios included situations such as when the victim is the respondent's own family member, the victim is involved in a motor vehicle accident with facial trauma, and the victim is an unkempt individual who appeared like a drug addict (see Table 1 for a complete list of scenarios).

Realizing the potential vulnerability of the students as study subjects, we emphasized to them that this was an anonymous, voluntary survey. Students who refused to participate simply returned the form in an opaque envelope provided. We allowed them to fill out the form in an unmonitored environment because we did not want them to feel that they were doing it under duress or scrutiny. We also made clear in briefings that should they agree to participate in the survey, they were implying that they consented to allow their anonymous answers to be pooled for statistical analysis and any subsequent publications.

We chose to obtain the opinions of the final year medical and dental students because we believe, as the immediate future batch of new doctors and dentists, they should set an example for the public. Our argument is that, if our future health care providers are not willing to perform bystander CPR in the out-of-hospital setting, how much more then can we expect from our general public?

For selected analysis, "definitely yes" and "probably yes" variables were recoded as "positive responses," 
Table 1 Questions asked in the survey form

\section{Section A}

Demographic data:

Age

Gender: male/female

Dental/medical student?

Race

Section B

General question:

In general, what would you do if you witness someone having cardiopulmonary arrest? (Assume there is no scene danger and help has already been summoned)

A. Pretend you do not see it and walk away

B. Offer to call the emergency medical services, but be afraid to tell the crowd you are a health care student and/or afraid to offer CPR (while you silently hope that someone else would do the CPR or the ambulance would have arrived quickly)

C. Tell the crowd that you are a health care student and offer to do CPR and advise someone to call the emergency medical services

Section $\mathrm{C}$

Category I (CC + MMV)

No pocket mask, performing both chest compression and mouth-to-mouth ventilation

"You are walking alone. You witnessed victim A having cardiopulmonary arrest (no breathing, no pulse) right in front of you. You have no pocket mask with you. Assuming no scene danger and help has already been summoned, would you perform CPR (both mouth-to-mouth and chest compression) if victim A were

Scenario 1: your own family member?

Scenario 2: your close friend?

Scenario 3: a stranger of different gender from you?

Scenario 4: a stranger of different race from you?

Scenario 5: a stranger of different gender and race from you?

Scenario 6: a stranger involved in a motor vehicle accident with facial trauma/bleeding?

Scenario 7: a stranger who is a child?

Scenario 8: a stranger who is an elderly man/woman from an old folks home?

Scenario 9: an unkempt stranger (appeared to look like a drug addict to you)?

Scenario 10: a person with whom you have a personal dispute?

For each scenario, rate your response with only one of the four options below:

A. "Definitely yes"

B. "Probably yes"

C. "Probably no"

D. "Definitely no"

Category 2 (CC + PMV)

For this category, the above ten hypothetical scenarios are repeated, but this time assuming that the respondent has a pocket mask and is asked to perform mask-to-mouth ventilation besides chest compressions

Category 3 (CC)

For this category, the above ten hypothetical scenarios are repeated, but this time, assuming that the respondent has no pocket mask and is asked to perform chest compressions only

whereas "probably no" and "definitely no" were recoded as "negative responses." The McNemar test was applied for analysis of dependent categorical variables, whereas the chi-square test or Fisher exact test was applied for analysis of independent categorical variables. All statistical analysis was computed using Statistical Package for the Social Sciences $\left(\operatorname{SPSS}^{\circledR}\right)$ Version 12.0.1.

\section{Results}

Of the 160 medical students, 148 responded (92.5\%), and 56 of the 60 dental students responded (93.3\%). The majority of the students are Malays, and there were more female respondents than male. These facts merely reflect the demographic makeup of our university intake. When asked the general question "What would you do if you witness a cardiac arrest in an out-of-hospital setting?" only $51.4 \%$ of the medical students and $45.5 \%$ of the dental students said that they would tell the crowd that they are health care students and offer to perform CPR, whereas $48.6 \%$ of the medical students and $50.9 \%$ of the dental students said that they would just offer to call the emergency medical services but be afraid to offer to perform CPR. Two (3.6\%) of the dental students said that they would just silently walk away from the scene (Table 2). 
Table 2 Demographic data of the respondents

\begin{tabular}{lll}
\hline Variables & Medical students & Dental students \\
\hline Response rate & $148 / 160(92.5 \%)$ & $56 / 60(93.3 \%)$ \\
Age (in years) & $23.93 \pm 0.90$ & $23.33 \pm 0.77$ \\
Race & $109(73.6 \%)$ & $47(85.5 \%)$ \\
Malay & $37(25.0 \%)$ & $5(9.0 \%)$ \\
Chinese & $1(0.7 \%)$ & - \\
Indians & $1(0.7 \%)$ & $3(5.5 \%)$ \\
Other indigenous races & $45(30.4 \%)$ & $7(12.7 \%)$ \\
Gender & $103(69.6 \%)$ & $48(87.3 \%)$ \\
Male & & $2(3.6 \%)$ \\
Female & - & $28(50.9 \%)$ \\
General question: What would you do if you witness a cardiac arrest? & $72(48.6 \%)$ & $25(45.5 \%)$ \\
A. Walk away & $76(51.4 \%)$ & \\
B. Offer to call ambulance but be afraid to offer to perform CPR & \\
C. Perform CPR & & \\
\hline
\end{tabular}

In the CC + MMV category, we found that, except for the scenarios where the victim is a family member or a close friend, all other scenarios show a similar trend where the number of "definitely yes" and "probably yes" answers are dismally low (Table 3).

However, comparing CC + PMV versus CC + MMV, we found that the number of positive responses (recoded from "definitely yes" and "probably yes") are significantly higher in all scenarios in the CC + PMV category. A comparison between $\mathrm{CC}$ and $\mathrm{CC}+\mathrm{MMV}$ categories also shows a similar trend. The only scenario where there is no statistically significant result shown in these analyses is the scenario where the victim is the respondent's own family member as the number of positive responses is equally high for all three categories. (Tables 4 and 5).

Not only that, comparing CC + PMV versus CC categories, we found that the number of positive responses is also significantly higher in the CC category in these four scenarios: victim who is of different gender and race ( 94.6 versus $87.2 \%, P=0.004$ ), victim who is involved in a motor vehicle accident with facial trauma $(89.2$ versus $69.5 \%, P<$ 0.001 ), victim who is an unkempt stranger who looks like a drug addict (79.8 versus $50.7 \%, P<0.001)$, and victim who has a personal dispute with the respondent ( 92.1 versus $82.3 \%, P<0.001$ ) (Table 6).

Interestingly, we also found that when the respondent's gender is female, the number of positive responses is also significantly lower in the scenario of a victim who is of different gender as compared to a male respondent responding to a female victim. This happened in both $\mathrm{CC}+$ MMV (34.4 in female respondents versus $75.0 \%$ in male respondents, $P<0.001)$ and the CC + PMV (90.7 versus $100 \%$ in male respondents, $P=0.023$ ) categories. This significance was not observed in the $\mathrm{CC}$ technique (Table 7).

\section{Discussion}

Prompt response in giving effective chest compressions and early defibrillation is of utmost importance in optimizing the chance of survival of a cardiac arrest victim [7]. However, from our survey, only about half of our students said that they would be willing to perform CPR when they witnessed a cardiac arrest in front of them. Our argument is, if our students are not willing to give CPR despite that they had just completed the BLS and ACLS training, how much then can we expect them to be willing to perform CPR in months or years ahead after the completion of the BLS and ACLS? Studies had shown that the retention of knowledge and skills of CPR declines over time [23-25]. Furthermore, the students had been exposed to the practices and skills of BLS at least twice in the medical school. This is a disturbing trend to us as these students represent the immediate future doctors and dentists in our country. And often, these new doctors are the first ones to be called to attend to a cardiac arrest $[12,26,27]$. Many of these newly graduated doctors had not been shown to be competent enough to perform adequate resuscitation [27-30].

Except for victims who are their own family members or close friends, most students in our survey gave a negative response to performing CC + MMV. This has been demonstrated in similar previous surveys [1-5]. However, what had often not been studied in other surveys, but which we found to be additional deterrents in our community to performing $\mathrm{CC}+\mathrm{MMV}$, are sociocultural and gender differences. As mentioned, Malaysia is rich in her diverse and unique cultural heritage that is mutually respected due to her multiethnic population makeup. But these may ironically form some sociocultural reservations resulting in the reluctance among our students to perform CC + MMV on a victim of different gender and/or race. This is especially the case 
Table 3 The various responses to the ten hypothetical scenarios

\begin{tabular}{|c|c|c|c|}
\hline Victim who is a & $\mathrm{CC}+\mathrm{MMV}$ & $\mathrm{CC}+\mathrm{PMV}$ & $\mathrm{CC}$ \\
\hline \multicolumn{4}{|l|}{ Family member } \\
\hline Definitely yes & $176(86.7 \%)$ & $195(96.1 \%)$ & $195(96.1 \%)$ \\
\hline Probably yes & $25(12.8 \%)$ & $7(3.4 \%)$ & $7(3.4 \%)$ \\
\hline Probably no & $1(0.5 \%)$ & $1(0.5 \%)$ & $1(0.5 \%)$ \\
\hline Definitely no & - & - & - \\
\hline \multicolumn{4}{|l|}{ Close friend } \\
\hline Definitely yes & $119(58.6 \%)$ & $178(87.7 \%)$ & $192(94.6 \%)$ \\
\hline Probably yes & $66(32.5 \%)$ & $24(11.8 \%)$ & $9(4.4 \%)$ \\
\hline Probably no & $17(8.4 \%)$ & $1(0.5 \%)$ & $2(1.0 \%)$ \\
\hline Definitely no & $1(0.5 \%)$ & - & - \\
\hline \multicolumn{4}{|c|}{ Stranger of different gender } \\
\hline Definitely yes & $25(12.3 \%)$ & $114(56.2 \%)$ & $170(83.7 \%)$ \\
\hline Probably yes & $66(32.5 \%)$ & $75(36.9 \%)$ & $23(11.3 \%)$ \\
\hline Probably no & $94(46.3 \%)$ & $13(6.4 \%)$ & $9(4.5 \%)$ \\
\hline Definitely no & $18(8.9 \%)$ & $1(0.5 \%)$ & $1(0.5 \%)$ \\
\hline \multicolumn{4}{|c|}{ Stranger of different race } \\
\hline Definitely yes & $26(12.8 \%)$ & $118(58.1 \%)$ & $164(80.8 \%)$ \\
\hline Probably yes & $78(38.4 \%)$ & $69(34.0 \%)$ & $28(13.8 \%)$ \\
\hline Probably no & $82(40.4 \%)$ & $15(7.4 \%)$ & $10(4.9 \%)$ \\
\hline Definitely no & $17(8.4 \%)$ & $1(0.5 \%)$ & $1(0.5 \%)$ \\
\hline \multicolumn{4}{|c|}{ Stranger of different gender and race } \\
\hline Definitely yes & $18(8.9 \%)$ & $102(50.3 \%)$ & $163(80.3 \%)$ \\
\hline Probably yes & $58(28.6 \%)$ & $75(36.9 \%)$ & $29(14.3 \%)$ \\
\hline Probably no & $94(46.3 \%)$ & $23(11.3 \%)$ & $7(3.4 \%)$ \\
\hline Definitely no & $33(16.3 \%)$ & $3(1.5 \%)$ & $4(2.0 \%)$ \\
\hline \multicolumn{4}{|c|}{ Stranger sustaining facial trauma } \\
\hline Definitely yes & $7(3.4 \%)$ & $69(34.0 \%)$ & $141(695 \%)$ \\
\hline Probably yes & $27(13.3 \%)$ & $72(35.5 \%)$ & $40(19.7 \%)$ \\
\hline Probably no & $75(36.9 \%)$ & $45(22.1 \%)$ & $11(5.4 \%)$ \\
\hline Definitely no & $94(46.3 \%)$ & $17(8.4 \%)$ & $11(5.4 \%)$ \\
\hline \multicolumn{4}{|c|}{ Stranger who is a child } \\
\hline Definitely yes & $50(24.6 \%)$ & $137(67.5 \%)$ & $170(83.7 \%)$ \\
\hline Probably yes & $99(48.8 \%)$ & $58(28.6 \%)$ & $26(12.8 \%)$ \\
\hline Probably no & $47(23.2 \%)$ & $7(3.4 \%)$ & $3(1.5 \%)$ \\
\hline Definitely no & $7(3.4 \%)$ & $1(0.5 \%)$ & $4(2.0 \%)$ \\
\hline \multicolumn{4}{|c|}{ Stranger who is elderly } \\
\hline Definitely yes & $29(14.3 \%)$ & $110(54.2 \%)$ & $165(81.3 \%)$ \\
\hline Probably yes & $79(38.9 \%)$ & $73(36.0 \%)$ & $25(12.3 \%)$ \\
\hline Probably no & $77(37.9 \%)$ & $18(8.8 \%)$ & $8(3.9 \%)$ \\
\hline Definitely no & $18(8.9 \%)$ & $2(1.0 \%)$ & $5(2.5 \%)$ \\
\hline \multicolumn{4}{|l|}{ Unkempt stranger } \\
\hline Definitely yes & $6(3.0 \%)$ & $51(25.1 \%)$ & $107(52.7 \%)$ \\
\hline Probably yes & $7(3.4 \%)$ & $52(25.6 \%)$ & $55(27.1 \%)$ \\
\hline Probably no & $66(32.5 \%)$ & $58(28.6 \%)$ & $29(14.3 \%)$ \\
\hline Definitely no & $124(61.1 \%)$ & $42(20.7 \%)$ & $12(5.9 \%)$ \\
\hline \multicolumn{4}{|c|}{ Person with whom you have a personal dispute } \\
\hline Definitely yes & $26(12.8 \%)$ & $92(45.4 \%)$ & $148(72.9 \%)$ \\
\hline Probably yes & $82(40.4 \%)$ & $75(36.9 \%)$ & $39(19.2 \%)$ \\
\hline Probably no & $66(32.5 \%)$ & $24(11.8 \%)$ & $7(3.4 \%)$ \\
\hline Definitely no & $29(14.3 \%)$ & $12(5.9 \%)$ & $9(4.4 \%)$ \\
\hline
\end{tabular}

$C C+M M V$ chest compressions and mouth-to-mouth ventilation, $C C+P M V$ chest compressions and mask-to-mouth ventilation, $C C$ chest compressions only 
Table 4 Comparison of number of positive responses ${ }^{\mathrm{a}}$ between $\mathrm{CC}+\mathrm{MMV}$ and $\mathrm{CC}+\mathrm{PMV}^{\mathrm{b}}$

\begin{tabular}{|c|c|c|c|}
\hline If the victim is & $\mathrm{CC}+\mathrm{MMV}$ & $\mathrm{CC}+\mathrm{PMV}$ & $P$ value \\
\hline A family member & $201(99.0 \%)$ & $202(99.5 \%)$ & 1.0 \\
\hline A close friend & $186(91.6 \%)$ & $202(99.5 \%)$ & $<0.001$ \\
\hline A stranger of different gender & $91(44.8 \%)$ & $189(93.1 \%)$ & $<0.001$ \\
\hline A stranger of different race & $104(51.2 \%)$ & $187(92.1 \%)$ & $<0.001$ \\
\hline A stranger of different gender and race & $76(37.4 \%)$ & $177(87.2 \%)$ & $<0.001$ \\
\hline A stranger sustaining facial trauma & $34(16.7 \%)$ & $141(69.5 \%)$ & $<0.001$ \\
\hline A stranger who is a child & $149(73.4 \%)$ & $195(98.1 \%)$ & $<0.001$ \\
\hline A stranger who is elderly & $108(53.2 \%)$ & $183(90.1 \%)$ & $<0.001$ \\
\hline An unkempt stranger & $13(6.4 \%)$ & $103(50.7 \%)$ & $<0.001$ \\
\hline A person with whom you have a personal dispute & $108(53.2 \%)$ & $167(82.3 \%)$ & $<0.001$ \\
\hline
\end{tabular}

a Positive responses are recoded from the variables "definitely yes" and "probably yes"

${ }^{\mathrm{b}}$ The McNemar test was used for the analysis of these two dependent categorical variables

$C C+M M V$ chest compressions and mouth-to-mouth ventilation, $C C+P M V$ chest compressions and mask-to-mouth ventilation

regarding the gender factor, particularly for a female student responding to a male victim (Table 7).

Although it is true that using a pocket mask for ventilation also helps to significantly improve the willingness of our students to give CPR, pocket masks are not easily available to the general public in Malaysia. The most feasible and practical way is, of course, performing chest compression-only CPR. In fact, realizing the importance of prompt action and minimizing the delay in initiating chest compressions, the AHA recently issued a scientific statement in April 2008 calling for a bystander rescuer (regardless of whether trained or untrained) to immediately initiate chest compressions by pushing hard and fast in the center of the chest of an adult victim who suffered sudden cardiac arrest in an out-of-hospital setting [31]. Delays and interruptions should be minimized, and a rescuer should provide immediate chest compressions only unless he or she is confident and willing to give mouth-to-mouth ventilation without jeopardizing effective compressions. Chest compressions only have been demonstrated to be as effective as chest compressions plus ventilation [32-36] in the case of a sudden cardiac arrest of an adult in the out-ofhospital setting.

Various reasons have been elucidated on why bystanders refused to provide CPR, and these include a fear of disease transmission through MMV [31, 37-40] as well as panic and fear of causing further harm [31, 40]. Nevertheless, ultimately the decision whether the respondent would respond depends on whether the bystander perceives the event as an emergency situation that demands a moral responsibility to act upon it [41]. A bystander who believes that there are more capable people around will less likely offer his or her help - and this is often termed bystander apathy $[42,43]$. A bystander who lacks self-confidence in his or her ability will also be less likely to offer aid [3,5]. It has also been shown that a bystander who perceives serious consequences of not helping and a low risk of helping a particular victim will be more likely to help [2]. This explains why most bystanders are willing to help their own family members but not someone who appears like a drug

Table 5 Comparison of number of positive responses ${ }^{\mathrm{a}}$ between $\mathrm{CC}+\mathrm{PMV}$ and $\mathrm{CC}^{\mathrm{b}}$

\begin{tabular}{|c|c|c|c|}
\hline If the victim is & $\mathrm{CC}+\mathrm{MMV}$ & $\mathrm{CC}$ & $P$ value \\
\hline A family member & $201(99.0 \%)$ & $202(99.5 \%)$ & 1.0 \\
\hline A close friend & $186(91.6 \%)$ & $201(99.0 \%)$ & $<0.001$ \\
\hline A stranger of different gender & $91(44.8 \%)$ & $193(95.1 \%)$ & $<0.001$ \\
\hline A stranger of different race & $104(51.2 \%)$ & $192(94.6 \%)$ & $<0.001$ \\
\hline A stranger of different gender and race & $76(37.4 \%)$ & $192(94.6 \%)$ & $<0.001$ \\
\hline A stranger sustaining facial trauma & $34(16.7 \%)$ & $181(89.2 \%)$ & $<0.001$ \\
\hline A stranger who is a child & $149(73.4 \%)$ & $196(96.6 \%)$ & $<0.001$ \\
\hline A stranger who is elderly & $108(53.2 \%)$ & $190(93.6 \%)$ & $<0.001$ \\
\hline An unkempt stranger & $13(6.4 \%)$ & $162(79.8 \%)$ & $<0.001$ \\
\hline A person with whom you have a personal dispute & $108(53.2 \%)$ & $187(92.1 \%)$ & $<0.001$ \\
\hline
\end{tabular}

a Positive responses are recoded from the variables "definitely yes" and "probably yes"

${ }^{\mathrm{b}}$ The McNemar test was used for the analysis of these two dependent categorical variables

$C C+M M V$ chest compressions and mouth-to-mouth ventilation, $C C$ chest compressions only 
Table 6 Comparison of number of positive responses ${ }^{\mathrm{a}}$ between $\mathrm{CC}+\mathrm{PMV}$ and $\mathrm{CC}^{\mathrm{b}}$

\begin{tabular}{lll}
\hline If the victim is & CC + PMV & CC \\
\hline A family member & $202(99.5 \%)$ & $202(99.5 \%)$ \\
A close friend & $202(99.5 \%)$ & $201(99.0 \%)$ \\
A stranger of different gender & $189(93.1 \%)$ & $193(95.1 \%)$ \\
A stranger of different race & $187(92.1 \%)$ & $192(94.6 \%)$ \\
A stranger of different gender and race & $177(87.2 \%)$ & $192(94.6 \%)$ \\
A stranger sustaining facial trauma & $141(69.5 \%)$ & $181(89.2 \%)$ \\
A stranger who is a child & $195(96.1 \%)$ & $196(96.6 \%)$ \\
A stranger who is elderly & $183(90.1 \%)$ & $190(93.6 \%)$ \\
An unkempt stranger & $103(50.7 \%)$ & $162(79.8 \%)$ \\
A person with whom you have a personal dispute & $167(82.3 \%)$ & $187(92.1 \%)$
\end{tabular}

a Positive responses are recoded from the variables "definitely yes" and "probably yes"

${ }^{\mathrm{b}}$ The McNemar test was used for the analysis of these two dependent categorical variables

$C C+P M V$ chest compressions and mouth-to-mouth ventilation, $C C$ chest compressions only

addict with a high risk of human immunodeficiency virus (HIV) infection. These factors are possibly some of the most likely factors that contribute to the unwillingness among our students to perform bystander CPR. However, these remain yet to be validated in this study but they should serve as impetus for future works to be explored.

Several other limitations in this study are inevitable, as many of these are limitations inherent in the design of the study itself. Responses in hypothetical situations may not necessarily mirror actual clinical behavior. As mentioned earlier, several other factors (like the emotional makeup at that spur of the dire moment and the perceived selfconfidence) may as well influence a bystander's choice on whether to respond or not. Nevertheless, although intention or willingness to perform may not be the ideal indicators of future behavior, they are still good, practical survey tools that have been used in many other studies of health behaviors like dietary habits, HIV risk behaviors, etc. $[4,43,44]$.
Secondly, we admit that the ten hypothetical scenarios in the survey are too artificial and mechanically dissected. In actual situations, complexity is the rule and very often there would be overlaps of the scenarios. For example, although we gave the students two different scenarios-victim who is a family member and victim who is involved in a motor vehicle accident with facial trauma/bleeding - in actual fact, how would one respond to performing CPR + MMV for a family member who sustained facial trauma/bleeding?

Lastly, the fact that we allowed the students to complete the survey form in an unmonitored environment may actually have encouraged them to discuss with one another rather than revealing their own true intentions.

\section{Conclusion}

In conclusion, although there are a number of limitations in this survey, the results do shed light on some new

Table 7 A comparison of positive response rates among male and female respondents in responding to victim of a different gender

\begin{tabular}{|c|c|c|c|c|}
\hline & Positive responses & $P$ value & OR (male:female) & $95 \% \mathrm{CI}$ \\
\hline \multicolumn{5}{|c|}{ Category 1: CC + MMV } \\
\hline \multicolumn{5}{|c|}{ Respondent's gender } \\
\hline Male & $39 / 52(75.0 \%)$ & $<0.001$ & 5.71 & $2.80-11.64$ \\
\hline Female & $52 / 151(34.4 \%)$ & & & \\
\hline \multicolumn{5}{|c|}{ Category 2: CC + PMV } \\
\hline \multicolumn{5}{|c|}{ Respondent's gender } \\
\hline Male & $52 / 52(100 \%)$ & $=0.023$ & 1.10 & $1.05-1.16$ \\
\hline Female & $137 / 151(90.7 \%)$ & & & \\
\hline \multicolumn{5}{|c|}{ Category 3: CC } \\
\hline \multicolumn{5}{|c|}{ Respondent's gender } \\
\hline Male & $51 / 52(98.1 \%)$ & $=0.458$ & 3.232 & $0.40-26.15$ \\
\hline Female & $142 / 151(94.0 \%)$ & & & \\
\hline
\end{tabular}

$O R$ odds ratio, $C I$ confidence interval 
knowledge. Most of the similar surveys that had been done earlier were done outside of the Asian population $[1,2,4$, $5,37-39]$, with the exception of one done on a Japanese population [3]. The results of these studies cannot be overgeneralized and molded to our Asian community. There are certain peculiar and unique sociocultural factors that contribute to the unwillingness of our community to perform bystander CPR. As stated at the beginning of this paper, the ultimate aim of any BLS training is to translate the skill and knowledge into a practical willingness to perform bystander CPR in order to make the society a safer place to live in. Therefore, the CPR technique should be easy to learn, retain, and perform, especially for the general public. As such, the fact that the chest compressions-only technique has gained more importance with the announcement of the AHA scientific statement in April 2008 [31] is certainly good news for our Asian community responding to an adult stranger who collapses suddenly outside of the hospital.

\section{References}

1. Horowitz BZ, Matheny L (1997) Health care professionals' willingness to do mouth-to-mouth resuscitation. West J Med 167 (6):392-397

2. Brenner BE, Van DC, Cheng D, Lazar EJ (1997) Determinants of reluctance to perform CPR among residents and applicants: the impact of experience on helping behavior. Resuscitation 35 (3):203-211

3. Shibata K, Taniguchi T, Yoshida M, Yamamoto K (2000) Obstacles to bystander cardiopulmonary resuscitation in Japan. Resuscitation 44(3):187-193

4. Johnston TC, Clark MJ, Dingle GA, FitzGerald G (2003) Factors influencing Queenslanders' willingness to perform bystander cardiopulmonary resuscitation. Resuscitation 56(1):67-75

5. Jelinek GA, Gennat H, Celenza T, O’Brien D, Jacobs I, Lynch D (2001) Community attitudes towards performing cardiopulmonary resuscitation in Western Australia. Resuscitation 51(3):239-246

6. Spooner BB, Fallaha JF, Kocierz L, Smith CM, Smith SC, Perkins GD (2007) An evaluation of objective feedback in basic life support (BLS) training. Resuscitation 73(3):417-424

7. Stiell IG, Wells GA, Field B, Spaite DW, Nesbitt LP, De Maio VJ, Nichol G, Cousineau D, Blackburn J, Munkley D, LuinstraToohey L, Campeau T, Dagnone E, Lyver M, Ontario Prehospital Advanced Life Support Study Group (2004) Advanced cardiac life support in out-of-hospital cardiac arrest. N Engl J Med 351 (7):647-656

8. Cummins RO, Ornato JP, Thies WH, Pepe PE (1991) Improving survival from sudden cardiac arrest: the "chain of survival" concept. A statement for health professionals from the Advanced Cardiac Life Support Subcommittee and the Emergency Cardiac Care Committee, American Heart Association. Circulation 83 (5):1832-1847

9. Larsen MP, Eisenberg MS, Cummins RO, Hallstrom AP (1993) Predicting survival from out-of-hospital cardiac arrest: a graphic model. Ann Emerg Med 22(11):1652-1658

10. Eisenberg MS, Horwood BT, Cummins RO, Reynolds-Haertle R, Hearne TR (1990) Cardiac arrest and resuscitation: a tale of 29 cities. Ann Emerg Med 19(2):179-186
11. Hisamuddin NA, Hamzah MS, Holliman CJ (2007) Prehospital emergency medical services in Malaysia. J Emerg Med 32 (4):415-421

12. Chew KS, Idzwan ZM, Hisamuddin NA, Kamaruddin J, Wan Aasim WA (2008) Cardiopulmonary resuscitation: the short comings In Malaysia. Malays J Med Sci 14(2):23-25

13. Chew KS, Idzwan ZM, Hisamuddin NA, Kamaruddin J, Wan Aasim WA (2008) Outcomes of cardiopulmonary resuscitation performed in emergency department, Hospital Universiti Sains Malaysia. Med J Malaysia 63(1):4-8

14. Litwin PE, Eisenberg MS, Hallstrom AP, Cummins RO (1987) The location of collapse and its effect on survival from cardiac arrest. Ann Emerg Med 16(7):787-791

15. Lee HT, Low BT (1999) Education of the public on cardiopulmonary resuscitation: issues and challenges. Med J Malaysia 54(2):167-168

16. Rosnah R, Fadhli Y, Zainal AO (2005) Survey on first aid and CPR among health personnel in Malaysia. Non-Communicable Diseases Bulletin, Ministry of Health Malaysia 4(4):3-10

17. Malaysia. In: Central Intelligence Agency (CIA) The World Factbook. Available at https://www.cia.gov/library/publications/ the-world-factbook/geos/my.html. Accessed 4 Aug 2008

18. Malaysia. In: Wikipedia. Available at http://en.wikipedia.org/wiki/ Malaysia. Accessed 4 Aug 2008

19. Statistics-health facts 2006. In: Ministry of Health, Malaysia. Available at http://www.moh.gov.my/static/health_facts_2006.pdf. Accessed 4 Aug 2008

20. Undergraduate curriculum. In: The School of Medical Sciences, Universiti Sains Malaysia website. Available at http://www. medic.usm.my/undergraduate/index.php?page $=$ doctor. Accessed 4 Aug 2008

21. Harden RM, Sowden S, Dunn WR (1984) Educational strategies in curriculum development: the SPICES model. Med Educ 18 (4):284-297

22. ECC Committee, Subcommittees and Task Forces of the American Heart Association (2005) 2005 American Heart Association Guidelines for Cardiopulmonary Resuscitation and Emergency Cardiovascular Care. Circulation 112(24 Suppl):IV1-IV203

23. Gass DA, Curry L (1983) Physicians' and nurses' retention of knowledge and skill after training in cardiopulmonary resuscitation. Can Med Assoc J 128(5):550-551

24. Kaye W, Mancini ME (1986) Retention of cardiopulmonary resuscitation skills by physicians, registered nurses, and the general public. Crit Care Med 14(7):620-622

25. Verplancke T, De Paepe P, Calle PA, De Regge M, Van Maele G, Monsieurs KG (2008) Determinants of the quality of basic life support by hospital nurses. Resuscitation 77(1):75-80

26. Kaye W, Wynne G, Marteau T, Dubin HG, Rallis SF, Simons RS, Evans TR (1990) An advanced resuscitation training course for preregistration house officers. J R Coll Physicians Lond 24(1):51-54

27. Jensen ML, Hesselfeldt R, Rasmussen MB, Mogensen SS, Frost T, Jensen MK, Muijtjens A, Lippert F, Ringsted C (2008) Newly graduated doctors' competence in managing cardiopulmonary arrests assessed using a standardized Advanced Life Support (ALS) assessment. Resuscitation 77(1):63-68

28. Casey WF (1984) Cardiopulmonary resuscitation: a survey of standards among junior hospital doctors. J R Soc Med 77(11):921-924

29. Skinner DV, Camm AJ, Miles S (1985) Cardiopulmonary resuscitation skills of preregistration house officers. Br Med J (Clin Res Ed) 290(6481):1549-1550

30. Lum ME, Galletly DC (1989) Resuscitation skills of first year postgraduate doctors. N Z Med J 102(873):406-408

31. Sayre MR, Berg RA, Cave DM, Page RL, Potts J, White RD (2008) Hands-only (compression-only) cardiopulmonary resuscitation: a call to action for bystander response to adults who experience outof-hospital sudden cardiac arrest: a science advisory for the public 
from the American Heart Association Emergency Cardiovascular Care Committee. Circulation 117(16):2162-2167

32. Hallstrom A, Cobb L, Johnson E et al (2000) Cardiopulmonary resuscitation by chest compression alone or with mouth-to-mouth ventilation. N Engl J Med 342(21):1546-1553

33. Waalewijn RA, Tijssen JG, Koster RW (2001) Bystander initiated actions in out-of-hospital cardiopulmonary resuscitation: results from the Amsterdam Resuscitation Study (ARRESUST). Resuscitation 50(3):273-279

34. SOS-KANTO study group (2007) Cardiopulmonary resuscitation by bystanders with chest compression only (SOS-KANTO): an observational study. Lancet 369(9565):920-926

35. Iwami T, Kawamura T, Hiraide A et al (2007) Effectiveness of bystander-initiated cardiac-only resuscitation for patients with outof-hospital cardiac arrest. Circulation 116(25):2900-2907

36. Bohm K, Rosenqvist M, Herlitz J et al (2007) Survival is similar after standard treatment and chest compression only in out-ofhospital bystander cardiopulmonary resuscitation. Circulation 116 (25):2908-2912

37. Brenner B, Kauffman J (1993) Reluctance of internists and medical nurses to perform mouth-to-mouth resuscitation. Arch Intern Med 153(15):1763-1769

38. Brenner B, Stark B, Kauffman J (1994) The reluctance of house staff to perform mouth-to-mouth resuscitation in the inpatient setting: what are the considerations? Resuscitation 28(3):185-193

39. Brenner B, Kauffman J, Sachter JJ (1996) Comparison of the reluctance of house staff of metropolitan and suburban hospitals to perform mouth-to-mouth resuscitation. Resuscitation 32(1):5-12

40. Locke CJ, Berg RA, Sanders AB, Davis MF, Milander MM, Kern KB, Ewy GA (1995) Bystander cardiopulmonary resuscita- tion. Concerns about mouth-to-mouth contact. Arch Intern Med 155(9):938-943

41. Latane B, Darley J (1970) The unresponsive bystander: Why doesn't he help? Appleton-Century-Crofts, New York

42. Takooshian H, O'Conner PJ (1984) When apathy leads to tragedy: two Fordham professors examine 'Bad Samaritanism'. Social Action and the Law 10(1):26-27

43. Levine M (1999) Rethinking bystander nonintervention: social categorization and the evidence of witnesses at the James Bolger murder trial. Human Rel 52:1133-1155

44. Godin G, Kok G (1996) The theory of planned behavior: a review of its applications to health-related behaviors. Am J Health Promot 11(2):87-98

Keng Sheng Chew is an emergency physician and senior lecturer in emergency medicine in Universiti Sains Malaysia. His special interests include cardiopulmonary resuscitation, critical care interventions, and medical education in emergency medicine.

Mohd Noh Abu Yazid is an emergency physician and senior lecturer in emergency medicine in Universiti Sains Malaysia. His special interests include hyperbaric medicine, emergency trauma care, and prehospital care. 